\title{
Peach rootstock tolerance to excess zinc in sandy acidic soil
}

Brunetto $G{ }^{a}$, Tiecher $T L$ a, Hammerschmitt RKa, Basso Facco $D$ a, Ferreira PAA a, De Conti $L$ a, Oliveira Stefanello da Silva $L a$, Mayer $N A{ }^{b}$, Correa Antunes $L E b$, Cesco $S{ }^{c}$, Mimmo $T^{c *}$

${ }^{a}$ Federal University of Santa Maria, Santa Maria-Rio Grande do Sul, Brazil; ${ }^{b}$ Brazilian Enterprise for Agric. Research, Embrapa Temperate Agriculture, Pelotas, Brazil; ' Free University of Bolzano-Bozen, BolzanoBozen, Italy

*presenting author (tanja.mimmo@unibz.it)

In some areas dedicated to the cultivation of peach plants, soils are characterized by high levels of zinc ( $\mathrm{Zn}$ ) as a consequence of successive applications of Zn-containing fungicides and/or of animal manure as fertilizers. In these cases, the choice of the most appropriate rootstock is the prerequisite for the productive success of the orchard. Therefore, this work aimed at evaluating the tolerance of three peach rootstocks grown in soils characterized by different levels of $\mathrm{Zn}$ availability. To this purpose, samples of a Typic Hapludalf soil were collected in a natural grassland in southern Brazil. The soil was dried, sieved, and acidity and phosphorus and potassium contents were corrected. Afterwards, the soil was subjected to application of $0,15,30,60$ and $120 \mathrm{mg} \mathrm{Zn} \mathrm{kg}^{-1}$. In each treatment, three types of peach rootstocks (Tsukuba-1, Rigitano and Flordaguard) were grown in rhizoboxes using a completely randomized experimental design for 65 days. The dry matter production of leaves, branches and rootstock, as well as the increase in height and stem diameter were measured. Total contents of $\mathrm{Zn}$, iron, nitrogen, phosphorus, calcium and magnesium were analyzed in each organ and the photosynthetic pigments and catalase (CAT) activity were analyzed in the leaves. Concentrations of $\mathrm{Zn}$ increased linearly in all organs of all cultivars. However, the Tsukuba-1 rootstock presented greater sensitivity to high levels of $\mathrm{Zn}$ availability in soil, with a reduction in leaf dry matter production, chlorophyll $a$ and carotenoid contents, and CAT activity. Surprisingly, the Flordaguard rootstock showed an increase in height due to the increase in $\mathrm{Zn}$ applied to the soil. Differently, the development of Rigitano rootstock plants was unaffected by different levels of $\mathrm{Zn}$ availability.

Keywords: heavy metals, phytotoxicity, photosynthetic pigments, acidic soils, foliar fungicides 